\title{
MRI Evaluation of Patients with Empty Sella - A Retrospective Study K.S. Hegde Medical Academy, Mangalore
}

\author{
Mourish Asokan ${ }^{1}$, Rohini Avantsa², Alan Anchan ${ }^{3}$ \\ 1,2,3 Department of Radiodiagnosis, K. S. Hegde Medical Academy, Deralakatte, Mangalore, Karnataka, India.
}

\section{ABSTRACT}

\section{BACKGROUND}

Empty Sella is often an incidental finding in brain imaging studies. However, in the recent past, its association with hormonal and intracranial hypertension has been researched by various authors. The main purpose of the present study was to evaluate the MRI features of patients with empty sella presented for routine MRI brain imaging.

\section{METHODS}

This is a single-centre, hospital-based, observational, and retrospective study. MRI brain of 67 patients with empty sella was retrospectively reviewed from January 2012 to October 2020. All patients had been referred to the Department of Radiodiagnosis with clinical suspicion of intracranial pathology. The various manifestations and their complications were evaluated.

\section{RESULTS}

This present study comprised 39 males (58\%) and 28 females (42\%). The most common age group was 41 - 60 years with a mean age of 49 years. The most common presenting symptom was headache (34\%). In MRI brain study, $93 \%$ of the cases of empty sella was an incidental finding. In $24 \%$ of the patients, empty sella was associated with MRI features of intracranial hypertension and $13 \%$ with idiopathic intracranial hypertension. $62.5 \%$ of the patients with intracranial hypertension had complete empty sella compared to $82 \%$ of the patients with no features of intracranial hypertension and had partial empty sella even though the association was not statistically significant.

\section{CONCLUSIONS}

The significance of the MRI finding of an empty sella turcica can be determined using a combination of clinical and imaging findings.

\section{KEY WORDS}

Empty Sella, MRI, Intracranial Hypertension.
Corresponding Author: Dr. Mourish Asokan,

Flat No 205, Hill Streak Apartment, Gorigudda, Mangalore - 575002,

Karnataka, India.

E-mail:mouriashok16@gmail.com

DOI: $10.14260 /$ jemds/2021/587

How to Cite This Article:

Asokan M, Avantsa R, Anchan A. MRI evaluation of patients with empty sella - a retrospective study $K$. S. Hegde Medical Academy, Mangalore. J Evolution Med Dent Sci 2021;10(34):2879-2883, DOI: $10.14260 /$ jemds/2021/587

Submission 07-04-2021,

Peer Review 17-06-2021,

Acceptance 23-06-2021,

Published 23-08-2021.

Copyright (C) 2021 Mourish Asokan et al. This is an open access article distributed under Creative Commons Attribution License [Attribution 4.0 International (CC BY 4.0)] 


\section{BACKGROUND}

Empty sella is a condition in which the pituitary fossa is either completely or partially replaced by CSF fluid. On most occasions, it is an incidental finding in CT and MRI studies. Diaphragma sella defect has been studied in up to $50 \%$ of adults, 1,2 and the estimated overall incidence of an empty sella turcica studied on imaging is $12 \% .^{3}$ The sella turcica is a saddle-like compartment present at the base of the skull which contains the pituitary gland within. When the pituitary gland is compressed or flattened along the floor of the pituitary fossa, it cannot be detected on the MRI and CT which makes it look like an empty sella. This is called an empty sella syndrome. 4

Historically this term was first described for an enlarged pituitary fossa with little or no mass being detected on surgical exploration. Two types of empty sella are described based on aetiology - primary empty sella in which there is a deficiency in diaphragma sella which allows CSF into the sella compressing the pituitary gland and secondary empty sella which is either secondary to pituitary pathology or posttreatment. 4 Another type of classification is partial and complete empty sella depending on various grades of pituitary parenchymal compression by CSF containing space which can be seen on MRI images. Idiopathic intracranial hypertension (IIHT) is a syndrome of unknown aetiology that results in increased intracranial pressure without hydrocephalus or an intracranial lesion. Patients with IIHT presents with headache, tinnitus, diplopia and visual disturbances with papilledema. Imaging of the brain with CT or MRI is important in patients suspected with IIHT to exclude other causes of elevated intracranial hypertension like hydrocephalus or intracranial lesions. Imaging features support the diagnosis of IIHT in the absence of a cause for intracranial hypertension. The most common imaging features supporting IIHT are empty sella turcica, flattening of the posterior sclera, prominent CSF space around the optic nerve and intraocular protrusion of the optic nerve head. Thus, features of an empty sella in brain imaging adds additional support in diagnosing IIHT.5,6 Empty sella can be detected on CT images with CSF density within the pituitary fossa. MRI is the modality of choice for diagnosing the condition and associated abnormalities. Patients with empty sella are usually asymptomatic and with no hormonal disturbances. However, few patients present with hormonal disturbances and headaches. ${ }^{5}$ With this introduction the study was conducted to know the frequency of occurrence, common presenting symptoms and associated MRI features of empty sella.

\section{METHODS}

It was a retrospective, hospital-based and observational study of 67 patients done in the Department of Radiodiagnosis, K. S. Hegde Medical Academy, Mangalore from January 2012 to October 2020. The sample was collected from the computer data after obtaining approval from the institutional review board to review the patient's images and medical charts. Basic demographic data of the patients were noted. Patients with a history of pituitary disease and post-operative changes of the pituitary gland were excluded from the study. MRI technique -
All patients had MRI brain evaluation done on a 1.5 Tesla MR machine (Siemens Magnetom Avanto) using the following sequences. T1W, T2W, FLAIR, DWI, and SWI sequences in various planes.

\section{Clinical Parameters}

Presenting symptoms and clinical diagnosis.

\section{Imaging Evaluation}

The following parameters were reviewed from the patient's data. Presence of partial or complete empty sella, size of the pituitary fossa, morphology of sella turcica, herniation of suprasellar visual system, extra or intra-axial lesions and features of intracranial hypertension. The diagnosis of partial or complete empty sella was given based on the size of the compressed pituitary gland measured by vertical dimension [3 $\mathrm{mm}$ or less]. The total absence with no visible parenchymal signal on MRI was taken as a complete empty sella. These categories were done based on the system of Yuh et al. ${ }^{7}$

\section{Statistical Analysis}

The data was analysed and the results were presented using tables and graphs. Descriptive statistics and chi-square tests were used for analysis using SPSS.

\section{Ethical Statement}

Ethical clearance was obtained from the institutional review board to review patient's images and medical records.

\section{RESULTS}

Demographic and presenting features of patients with empty sella. The study included 67 patients with 39 males (58\%) and 28 females (42\%). The most common age group was 41 - 60 years with 30 patients ( $45 \%$ ), followed by 61 - 80 years with 22 patients (33\%), 21 - 40 years with 12 patients (18\%) and less than 20 years with 3 patients ( $4 \%$ ). Majority of the study population were males (58\%) who were in the 41 - 60 years age group. In our study majority of the patients presented with a history of headache, seen in 19 patients (28\%), followed by intracranial space-occupying lesions (either for metastatic workup or primary lesions) in 13 patients (20\%) and orbital symptoms in 5 patients (7.5\%). Other less frequent presenting symptoms were trigeminal neuralgia, evaluation for electrocution, neck pain, Parkinsonism, Wernicke's encephalopathy and altered sensorium [Table1].

\begin{tabular}{|ccc|}
\hline Presenting Symptom & No of Patients & $\begin{array}{c}\text { Percentage } \\
\text { (\%) }\end{array}$ \\
Headache & 19 & 28.35 \\
Weakness & 5 & 7.46 \\
Suspected intra / extra - axial tumours & 13 & 19.4 \\
Headache with vomiting & 4 & 5.97 \\
Psychiatry & 5 & 7.46 \\
Seizure & 2 & 2.98 \\
Orbital symptoms & 5 & 7.46 \\
Other symptoms & 14 & 20.89 \\
Total & $\mathbf{6 7}$ & $\mathbf{1 0 0}$ \\
\hline Table 1. Distribution of Patients According to \\
Major Presenting Symptoms \\
\hline
\end{tabular}




\section{MRI Features of Empty Sella}

The most common radiological features observed were of vascular aetiology, like periventricular small vessel ischemic changes, dilated ICA, amyloid angiopathy and infarcts (41\%) followed by cases of intracranial hypertension with (24\%). Intracranial space-occupying lesions constituted $21 \%$ of cases among which $80 \%$ were metastatic lesions and $7.4 \%$ presented with raised intracranial tension. Features of idiopathic intracranial hypertension were seen in 9 cases, hydrocephalus in 5 cases and normal pressure hydrocephalus (NPH) in 2 cases. Patients with cerebral atrophy (2 cases), spondylosis ( 3 cases), and a combination of intra-axial lesions with raised intracranial tension (5 cases) made another $15 \%$. Normal brain imaging findings were seen in $7.5 \%$ of patients (5 cases). Patients with orbital findings like optic neuritis were about $6 \%$ of the study group [Table 2].

\begin{tabular}{|ccc|}
\hline MRI Diagnosis & No of Patients & Percentage (\%) \\
\hline $\begin{array}{c}\text { Vascular cause } \\
\text { Extra axial / Intra-axial } \\
\text { lesions [primary and } \\
\text { metastasis] }\end{array}$ & 28 & 41.8 \\
Intracranial hypertension & 9 & 13.43 \\
Hydrocephalus & 16 & \\
NPH & 5 & 23.88 \\
Idiopathic & 2 & \\
Intra-axial masses with & 9 & 7.4 \\
raised IH & 5 & 5.97 \\
Optic neuritis & 4 & 7.4 \\
Normal brain & 5 & 7.4 \\
Spondylosis and atrophy & 5 & $51 \%$ \\
Complete empty sella & Type of Sella & $49 \%$ \\
Partial empty sella & 34 & \\
\hline Table 2. Distribution of Patients According to \\
Radiological Findings and Type of Empty Sella \\
\hline
\end{tabular}

Pituitary tissue height on T1W / T2W weighted images were categorized based on the classification system of Yuh et al. The maximum height of pituitary tissue observed in our study was $3 \mathrm{~mm}$ which was categorized as partial empty sella [Figure 1]. The complete empty sella was diagnosed when there was $<2 \mathrm{~mm}$ of pituitary tissue height or no parenchymal tissue seen [categories IV and V of study conducted by Yuh et al.] [Figure 2]. The study observed that the frequency of complete empty sella was $51 \%$ (34 cases) and partial empty sella which was about $49 \%$ (33 cases). Out of 16 patients who had MRI features of intracranial hypertension, $63 \%$ had complete empty sella and $37 \%$ had partial empty sella. Out of 51 patients without intracranial hypertension, $47 \%$ had complete empty sella and $53 \%$ had partial empty sella. Majority of patients with no features of intracranial hypertension showed partial empty sella. However, the association was not statistically proven [Table 3].

\begin{tabular}{|c|c|c|c|}
\hline & $\begin{array}{c}\text { Without Intracranial } \\
\text { Hypertension }\end{array}$ & $\begin{array}{l}\text { With Intracranial } \\
\text { Hypertension }\end{array}$ & Total \\
\hline $\begin{array}{l}\text { Complete empty } \\
\text { Sella }\end{array}$ & $24[70.5 / 47.05]$ & $10[29.41 / 62.5]$ & 34 \\
\hline Partial empty Sella & $27[81.81 / 52.94]$ & $6[18.18 / 37.5]$ & 33 \\
\hline Total & $51[76.11]$ & $16[23.88]$ & 67 \\
\hline \multicolumn{4}{|c|}{$\begin{array}{l}\text { Table 3. Distribution of Patients According to } \\
\text { Presence of Intracranial Hypertension }\end{array}$} \\
\hline hi - square $1.162,{ }^{*} p$ & $p$ value is 0.281 & & \\
\hline
\end{tabular}

The following measurements were recorded on the midsagittal T1 - weighted images: Estimated anteriorposterior length of the diaphragma sella (in millimetres), maximum anteroposterior dimension of the sella (in millimetres) and anteroposterior distance from the anterior diaphragma sella to the pituitary stalk (in millimetres) [Table 4]. Our study showed the average AP diameter of diaphragma sella as $9 \mathrm{~mm}$, AP diameter of sella as $12.7 \mathrm{~mm}$ and AP diameter of infundibulum as $12.7 \mathrm{~mm}$.

\begin{tabular}{|ccccc|}
\hline Measurement & Average & Range & \multicolumn{2}{c|}{ Distribution Number [N - 67] } \\
AP diameter of & $9 \mathrm{~mm}$ & & $7-9 \mathrm{~mm}$ & $38[57 \%]$ \\
Diaphragma Sella & SD -1.34 & $7.1-12 \mathrm{~mm}$ & $>9-11 \mathrm{~mm}$ & $24[36 \%]$ \\
& & & $>11 \mathrm{~mm}$ & $5[7 \%]$ \\
AP diameter of sella & $12.7 \mathrm{~mm}$ & $11-14 \mathrm{~mm}$ & $>11-13 \mathrm{~mm}$ & $24[36 \%]$ \\
& $\mathrm{SD}-1.64$ & & $>13 \mathrm{~mm}$ & $14[21 \%]$ \\
& & $<5 \mathrm{~mm}$ & $10[15 \%]$ \\
AP diameter of & $12.7 \mathrm{~mm}$ & \multirow{2}{*}{$3.1-8 \mathrm{~mm}$} & $5-7 \mathrm{~mm}$ & $43[64 \%]$ \\
infundibulum & SD -6.53 & & $>7 \mathrm{~mm}$ & $14[21 \%]$ \\
\hline \multicolumn{4}{r}{ Table 4. Distribution of AP Diameter of Diaphragm Sella, } \\
\multicolumn{4}{r}{ Sella and Infundibulum in Study Population. } \\
\hline
\end{tabular}

Our study observed no specific pattern or difference in the pituitary and sella measurements in patients with partial and complete empty sella. Pituitary infundibulum can be either perpendicular or laterally deviated corresponding to the type of empty sella. In our study, $75 \%$ of patients showed a perpendicular position of the pituitary infundibulum and $25 \%$ showed a lateral deviation of the pituitary infundibulum. The horizontal position of optic chiasm was seen in $70 \%$ of patients, inferior bowing of optic chiasm was seen in $25.5 \%$ of patients and angulation of optic chiasm was seen in $4.5 \%$ of patients. Horizontal shape of sellar floor was seen in $55 \%$ of patients, right angulation of sellar floor was seen in $11 \%$ of patients and sloping of sellar floor was seen in $34 \%$ of patients. Even though there was no statistically proven significance, the inferior bowing and angulation of optic chiasm were more frequent in patients with complete empty sella [Table 5].

\begin{tabular}{|c|c|c|c|c|}
\hline & Findings & $\begin{array}{l}\text { Number and } \\
\% \text { of Patients }\end{array}$ & $\begin{array}{c}\text { Partial ESN } \\
{[\% \mathrm{~h} / \mathrm{v}]}\end{array}$ & $\begin{array}{c}\text { Complete ESN } \\
{[\% \mathrm{~h} / \mathrm{v}]}\end{array}$ \\
\hline \multirow[b]{2}{*}{$\begin{array}{c}\text { Pituitary } \\
\text { infundibulum }\end{array}$} & Perpendicular & $50[74.62]$ & $26[52 / 79]$ & $24[48 / 70.6]$ \\
\hline & $\begin{array}{c}\text { Lateral } \\
\text { deviation }\end{array}$ & 17 [25.37] & $07[41 / 21]$ & 10 [59 / 29.4] \\
\hline \multirow{3}{*}{ Optic chiasm } & Horizontal & 47 [70.149] & $29[62 / 88]$ & $18[38 / 53]$ \\
\hline & Inferior bowing & $17[25.37]$ & $04[23.5 / 12]$ & $13[76.5 / 38$ \\
\hline & Angled & $03[4.5]$ & 00 & 03 [100/9] \\
\hline \multirow{3}{*}{ Sellar floor } & Horizontal & $37[55]$ & 18 [49 / 55] & $19[51 / 56]$ \\
\hline & $\begin{array}{c}\text { Right } \\
\text { angulation }\end{array}$ & $07[11]$ & 04 [57 / 12] & $03[43 / 9]$ \\
\hline & Sloping & $23[34]$ & 11 [48 / 33] & 12 [52 / 35] \\
\hline \multicolumn{5}{|c|}{$\begin{array}{l}\text { Table 5. Distribution of Patients According to } \\
\text { Anatomical Features of Empty Sella }\end{array}$} \\
\hline
\end{tabular}

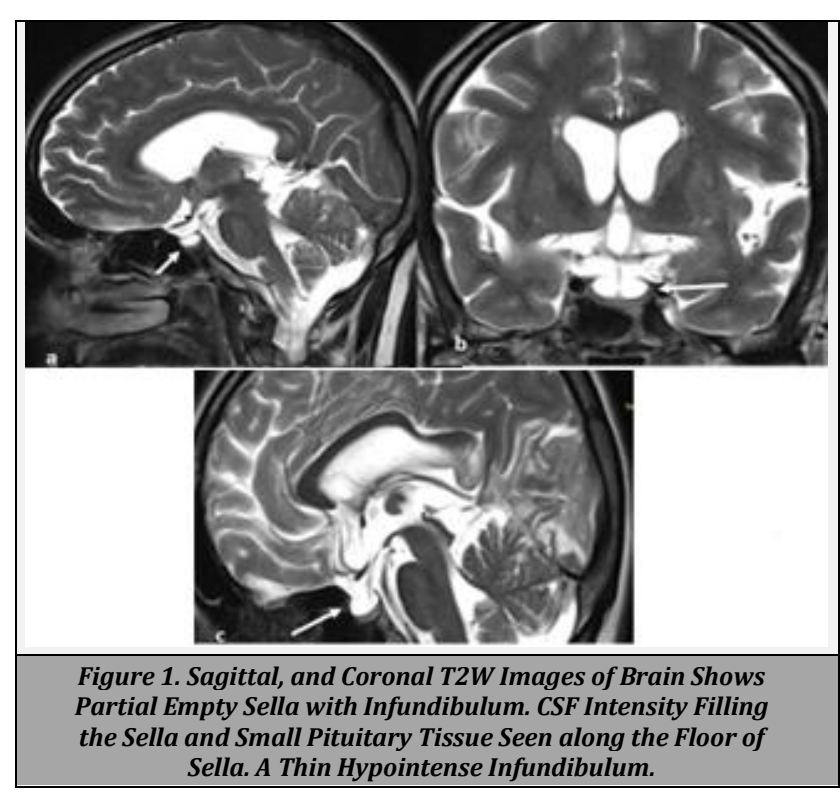




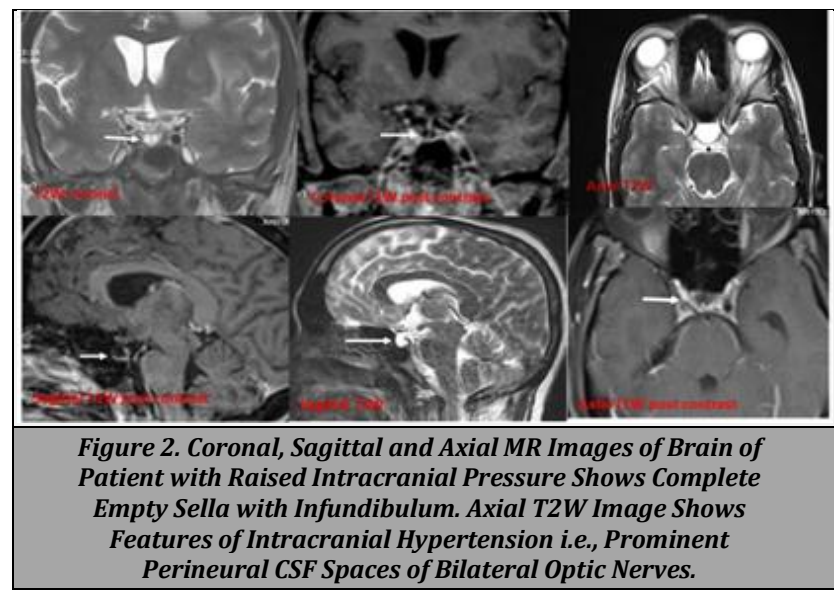

DISCUSSION

The sella turcica is a midline concavity in the basisphenoid of the central skull base that contains the pituitary gland. The sella is entirely embedded within the sphenoid bone. The anterior borders of the sella are formed by the tuberculum sella and anterior clinoid processes of the lesser sphenoid wing, whereas the posterior border is formed by the dorsum sellae. The top of the dorsum sellae expands slightly posteriorly and laterally to form the posterior clinoid processes, which in turn form the upper margin of the clivus.

Part of the sphenoid sinus roof forms the sellar floor, which is partially or completely aerated. The cavernous segments of the internal carotid arteries lie in shallow bony grooves (the carotid sulci) located inferolateral to the pituitary fossa. A small circular dural shelf, the diaphragma sella, forms a roof over the sella that almost covers the pituitary gland. The diaphragma sella has a variable sized central opening, the diaphragmatic hiatus which transmits the pituitary stalk. The mean diameter of the diaphragmatic hiatus is $7 \mathrm{~mm}$.

Empty sella was the term first given by Busch in $1951 .^{8}$ Later on, the term "empty sella" has been used to describe spectrum of findings related to the bony sella turcica and pituitary gland, ranging from mild superior concavity of the pituitary gland to an apparent absence of the pituitary gland and CSF expansion of the bony confines of the sella turcica. When some amount of pituitary gland is visible it is called "partial empty sella". During the routine examination of brain MRI study, some degree of empty sella is observed, which is an incidental finding most often. However, according to many previous studies, it can also present secondary to idiopathic intracranial hypertension. ${ }^{9}$

In this study, $46 \%$ of the study group was above 41 years, with a mean age of 49 years and among them $58 \%$ were males. However, previous studies reported that empty sella was 4 times more common in females than in males. ${ }^{10}$ In our study the most common presenting symptom observed was headache with a frequency of $28 \%$ and among those, $6 \%$ presented with associated vomiting. All the patients who were diagnosed to have features of raised intracranial hypertension presented with a history of headache which also could be due to venous sinus stenosis and increased pressure on the meninges. The other indication for MR imaging was an evaluation for intracranial space-occupying lesions which were about $19 \%{ }^{11}$ This could be because our hospital being a tertiary care centre, patients would be referred and evaluated for metastatic workup and treatment. This was also supported by more than above 40 years age group study population (78 $\%)$. Other less frequent symptoms were related to orbit and psychiatry. In our study, $7 \%$ of patients presented with orbital symptoms and another $7 \%$ were with Parkinsonism, Wernicke's encephalopathy and behavioural changes.

In one of the studies published by Col Jyotindu Debnath et al. $3.3 \%$ of empty sella patients presented with hormonal disturbance. In our study, the patient's records revealed no symptoms / history related to hormonal disturbances and no recorded treatment history related to the hormonal disturbances. Primary empty sella is most commonly associated with idiopathic intracranial hypertension and in this condition diagnosing empty sella has high radiological significance 9,12 In our study, $51 \%$ of the patients had complete empty sella and $49 \%$ of the patients had partial empty sella. $24 \%$ of patients with empty sella had associated MRI features of increased intracranial hypertension like prominent subarachnoid space around the optic nerve, flattening of the posterior globe and protrusion of the optic nerve papilla into the posterior globes. $13 \%$ had features of idiopathic intracranial hypertension [Figure3]. According to Agid and Farb et al. posterior globe flattening is the only sign that strongly suggests the diagnosis of IIH (specificity, $100 \%$; sensitivity, $43.5 \%$; positive likelihood ratio, 49:7).

Our study results show that out of 16 patients with MRI features of increased intracranial hypertension, $63 \%$ showed complete empty sella and $37 \%$ with partial empty sella, whereas $82 \%$ of the patients with partial empty sella showed no features of intracranial raised pressure. However, the association was not statistically significant. In our study even though there was increase in frequency of angulation and inferior bowing of optic chiasm in patients with complete empty sella, the other MRI measurements related to sella, diaphragm sella, features of empty sella like position of infundibulum, optic chiasma, and sella floor shape did not differ between partial empty sella and complete empty sella and also empty sella associated with intracranial hypertension. ${ }^{13}$

These changes like herniation of suprasellar visual system were also described by Kaufman et al.14 Other anatomical variations like the appearance of infundibulum and sellar floor were not reliable indicators according to the previous studies ${ }^{15,16}$ Pituitary infundibular deviation was found in $46 \%$ of 50 random patients studied by coronal MRI by Ahmadi H. et al. ${ }^{17}$ due to eccentric position of the pituitary gland or eccentric insertion of the stalk of the midline. A lateral tilt of the infundibulum was also due to lateral displacement of the pituitary gland. The results of the study suggested that empty sella could be an incidental finding and can occur in normal individuals. The symptoms and associated findings caused by the associated diseases may be attributed to co-existing empty sella. 


\section{CONCLUSIONS}

In routine MRI brain imaging, diagnosis of empty sella is considered as an incidental finding. The significance of the MRI finding of an empty sella turcica can be determined using a combination of information such as patient's age and sex, headache, visual symptoms, and papilledema and correlating orbital findings of IIH.

\section{Limitations}

There are several limitations to this study. A major limitation is that the clinical symptoms and diagnosis were based on a retrospective review of electronic records. It is possible that some of the cases of incidental empty sella were not appropriately diagnosed as IIH. Hormonal profile of the cases was not available to be included in the study, as the study was focused on retrospective analysis of MRI reports only.

Data sharing statement provided by the authors is available with the full text of this article at jemds.com.

Financial or other competing interests: None.

Disclosure forms provided by the authors are available with the full text of this article at jemds.com.

\section{REFERENCES}

[1] Sage MR, Blumbergs PC, Fowler GW. The diaphragma sellae: its relationship to normal sellar variations in frontal radiographic projections. Radiology 1982;145(3):699-701.

[2] Sage MR, Blumbergs PC, Mulligan BP, et al. The diaphragma sellae: its relationship to the configuration of the pituitary gland. Radiology 1982;145(3):703-8.

[3] Foresti M, Guidali A, Susanna P. Primary empty sella: incidence in 500 asymptomatic subjects examined with magnetic resonance (in Italian). Radiol Med 1991;81(6):803-7.

[4] Melmed S, Kleinberg D, Ho Ken. Pitutary physiology and diagnostic evaluation. Chap - 8. In: Kronenberg HM,
Melmed S, Polonsky KS, et al. eds. Williams textbook of Endocrinology. 12 $2^{\text {th }}$ edn. Philadelphia: Elsevier 2011.

[5] Debnath J, Ravikumar R, Sharma V, et al. 'Empty sella' on routine MRI studies: an incidental finding or otherwise? Med J Armed Forces India 2016;72(1):33-7.

[6] Ghatnatti V, Sarma D, Saikia U. Empty sella syndromebeyond being an incidental finding. Indian J Endocrinol Metab 2012;16(Suppl 2):S321-S3.

[7] Yuh WT, Zhu M, Taoka T, et al. MR imaging of pituitary morphology in idiopathic intracranial hypertension. J Magn Reson Imaging 2000;12(6):808-13.

[8] Bush W. Die morphologie der sella turcica und itse beziehungen zue hypophyse. Virchows Arch Path Anat Physiol 1951;320:437-58.

[9] Saindane AM, Lim PP, Aiken A, et al. Factors determining the clinical significance of an "empty" sella turcica. AJR Am J Roentgenol 2013;200(5):1125-31.

[10] Osborn AG, Salzman KL, Katzman G, et al. Osborn's Brain imaging, pathology and anatomy. $2^{\text {nd }}$ edn. USA: Elsevier Publication 2009: p. 992.

[11] Kim JH, Ko JH, Kim HW, et al. Analysis of empty sella secondary to the brain tumors. J Korean Neurosurg Soc 2009;46(4):355-9.

[12] Friedman DI, Jacobson DM. Diagnostic criteria for idiopathic intracranial hypertension. Neurology 2002;59(10):1492-5.

[13] Agid R, Farb RI, Willinsky RA, et al. Idiopathic intracranial hypertension: the validity of cross-sectional neuroimaging signs. Neuroradiology 2006;48(8):521-7.

[14] Kaufman B, Tomsak RL, Kaufman BA, et al. Herniation of the suprasellar visual system and third ventricle into empty sellae: morphologic and clinical considerations. Am J Neuroradiology 1989;10:65-76.

[15] Silbergleit R, Junck L, Gebarski SS, et al. Idiopathic intracranial hypertension (pseudotumor cerebri): MR imaging. Radiology 1989;170(1):207-9.

[16] Buchfelder M, Brockmeier S, Pichl J, et al. Results of dynamic endocrine testing of hypothalamic pituitary function in patients with primary "empty" sella syndrome. Horm Metab Res 1989;21(10):573-6.

[17] Ahmadi H, Larrson EM, Jinkins JR. Normal pituitary gland: coronal MR imaging of infundibular tilt. Radiology 1990;177(2):389-92. 